\title{
RADIOGRAPHY MONITORING OF OSTEOCONDUCTION AND OSTEOINDUCTION OF ORTHOTOPIC ALLOGRAFT AUTOCLAVED COVERED WITH PROPOLIS
}

\author{
Boudra Abdellatif $^{1}$--- Hamdi Mohamed ${ }^{2}$--- Amara Karim ${ }^{3}$--- Bouknine Asma ${ }^{4}$ \\ 'Ibn Khaldoun University, Veterinary Institute of Tiaret, surgery service, Agro-industrial department manager of Mahassil company \\ NH group, Algeria \\ ${ }_{1,2, s}$ Ibn Khaldoun University, veterinary institute of Tiaret, surgery service, Algeria
}

\begin{abstract}
The veterinarian orthopedic surgeon is often faced to the loss of bone substance in diaphyseal region of long bones. Our study is based on a biological approach to the filling of segmental bone loss by implanting an autoclaved orthotopic allograft of one centimeter length covered and uncovered with propolis in the femoral diaphysis under general anesthesia and sterile condition. The experiment involved eight adult dogs, from local breed and different sex; split into two groups. An autoclaved allograft without propolis was implanted for the first animals group (control group) then the same graft has been implanted to the second animals group. The aim of our study is to determine the osteoinductive and osteoconductive allograft covered with propolis, to follow clinically and radiologically the incorporation of the autoclaved graft. The results showed that the use of a graft covered with propolis accelerated the osteoinductive and osteoconductive process, this is reflected by an early passage of the callus. The use of a thin layer of propolis on a autoclaved allograft, stimulated peripheral and spinal osteoinduction, and accelerated osseointegration at both proximal and distal interfaces, this phenomenon can be controlled depending on the amount used of propolis on the graft.
\end{abstract}

Keywords: Propolis, Autoclaved allograft, Osteoinduction, Osteoconduction, Radiography.

\section{Contribution/ Originality}

This study is one of very few studies which has investigated the both phenomena osteoinduction and the osteconduction of autoclaved allograft and we have used in our study the extract propolis as purchased from France in vivo and highlight its advantages too.

\section{INTRODUCTION}

The treatment of bone loss with a graft is under estimated, however it can potentially help patients achieve a faster return to normal activities [1]. The bone graft is a ubiquitous material in orthopedic surgery since it is used in all sub-specialties and majorities of anatomical regions [2] Even today, autologous transplantation remains the reference method, despite its disadvantages (increased duration of intervention and surgical risk, residual pain, limited quantity) [3]. The allograft is an alternative to the massive segmental bone loss but often faces several constraints, 
including the problem of infection, failure of incorporation and the decrease with time of mechanical properties resulting in the fracture of the graft [4].

\section{MATERIALS AND METHODS}

\subsection{Experimental Animals}

Our experiment was conducted on eight (08) local breed dogs (male and female) aged between 6 and 12 months, the average body weight is estimated at $15 \mathrm{~kg}$. All animals were dewormed by using Flubendazole at $75 \mathrm{mg} / \mathrm{kg}$ (FLUVERMAL ${ }^{\circledR}$; Janssen-Cilag ; France; 100mg/comprimé) and a control collar was secured around dog's neck to prevent infestation of external parasites. Thereafter, the animals were placed in separate cages and left for an accommodation period of 15 days. Preparation of orthotopic allografts put in special bags has required the use of an autoclave and a pure extract of propolis and the radiographic monitoring was performed using digital radiology.

\subsection{Graft Preparation}

The graft is obtained from the diaphysis of the left femur of a dog euthanized, after removal of the periosteum, bone and muscle insertions of residues, the shaft is cut by using a stainless metal saw into fragments of $1 \mathrm{~cm}$ length. The grafts in the control group are put directly in special sealed bags(SteriCleanISO 11607 REF 230112 LOT 3006715062011 20cm /200 m). Other grafts are similarly prepared, except an additional step wherein the propolis (Arkogélule Arkopharma 45 capsules 22.3gr, 250mg/capsule France $\mathrm{N}^{\circ}$ de lot $\mathrm{BCP} 00865 \mathrm{~B}$ ) is applied to the integrity of the graft before it is placed in bags for sterilization. The grafts are prepared then autoclaved at a temperature of $121{ }^{\circ} \mathrm{C}$ (Webeco $\mathrm{GmbH}$ type A No 919995 made in Germany Watt 2700 Amp 12).

\subsection{Anesthetic Protocol}

Anesthetic premedication protocol is begun with $0.01 \mathrm{mg} / \mathrm{Kg}$ atropine injected subcutaneously (Atropine ${ }^{\circledR}$ sulfate $(0,1 \%)$ : Lab RENAUDIN; $\mathrm{N}^{0} 112992$; France), followed after 15 minutes by a double injection intramuscularly of acepromazine (CALMIVET ${ }^{\circledR}(0.5 \%)$ :

Vetoquinol ; France) and buprenorphine (Temgesic ${ }^{\circledR}(0,3 \mathrm{mg} / \mathrm{ml})$ :Schering-plough; LevalloisPerret; France) at $0.2 \mathrm{mg} / \mathrm{kg}$ and $0,02 \mathrm{mg} / \mathrm{Kg}$ respectively. Induction is achieved by a single slow intravenous injection of propofol in an amount of $8 \mathrm{mg} / \mathrm{Kg}$.Just before starting the operation, half mixture of tiletamine and zolazepam at a rate of $15 \mathrm{mg} / \mathrm{kg}$ was injected to maintain anesthesia during surgery, the second half was injected 45 minutes after and if necessary of small amounts may be added throughout the operation. 


\subsection{Surgical Technique}

The spindle is inserted through the proximal end with a mandrel Jacobson, it engages retrogradely into the medullary canal of the proximal portion held by a clamp to bone, the diameter of the pin must represent $50-70 \%$ of the medullary cavity. The pin is slid along the medullary canal until the trochanteric fossa ,a skin incision is made at the raised portion by the spindle and it outputs the three quarters of the pin through this opening .Once the proximal and distal portion of the bone are drilled using a Steinmann pin

$2 \mathrm{~mm}$ diameter, in order to get the stainless wire of $0.6 \mathrm{~mm}$ in diameter to produce a hemi strapping.

Figure-1.intraoperative photograph showing the maintenance of the graft using a wire, the white arrow indicates a remote node clamping graft.

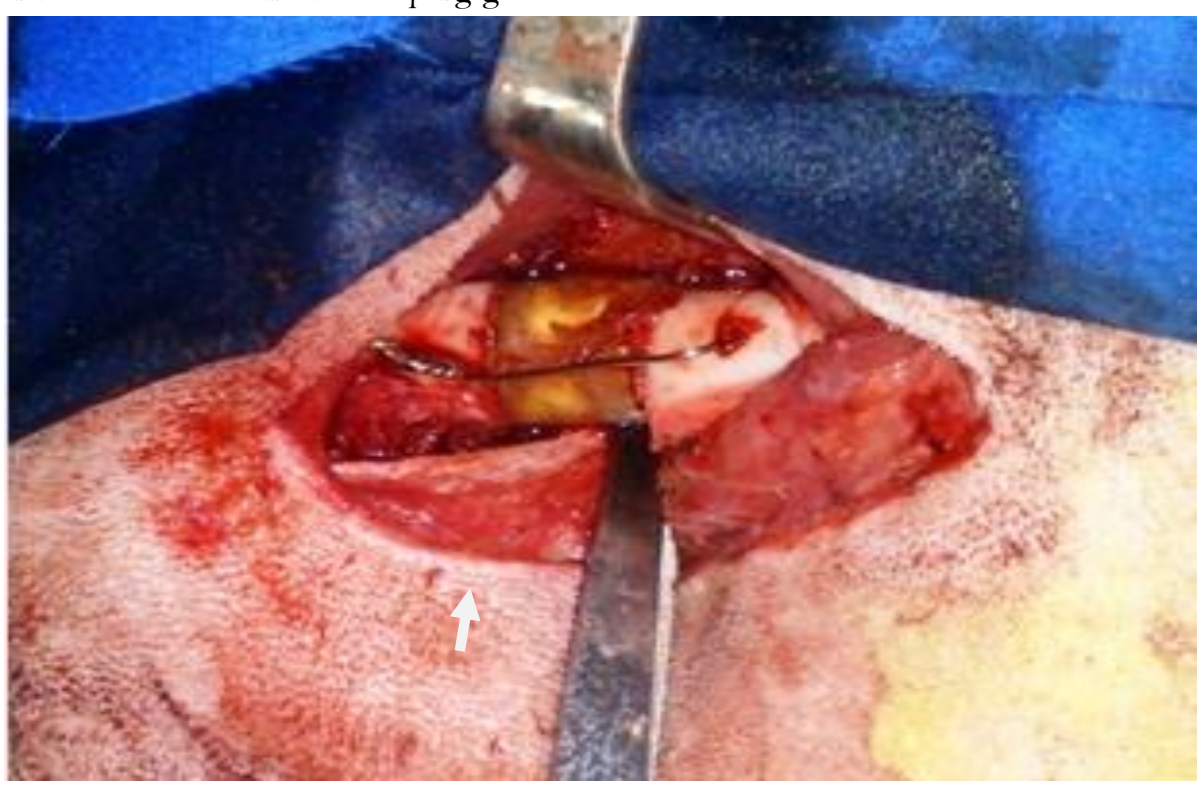

Figure-2.intraoperative photograph showing the manual section of one centimeter of the femoral shaft with the wire saw. 


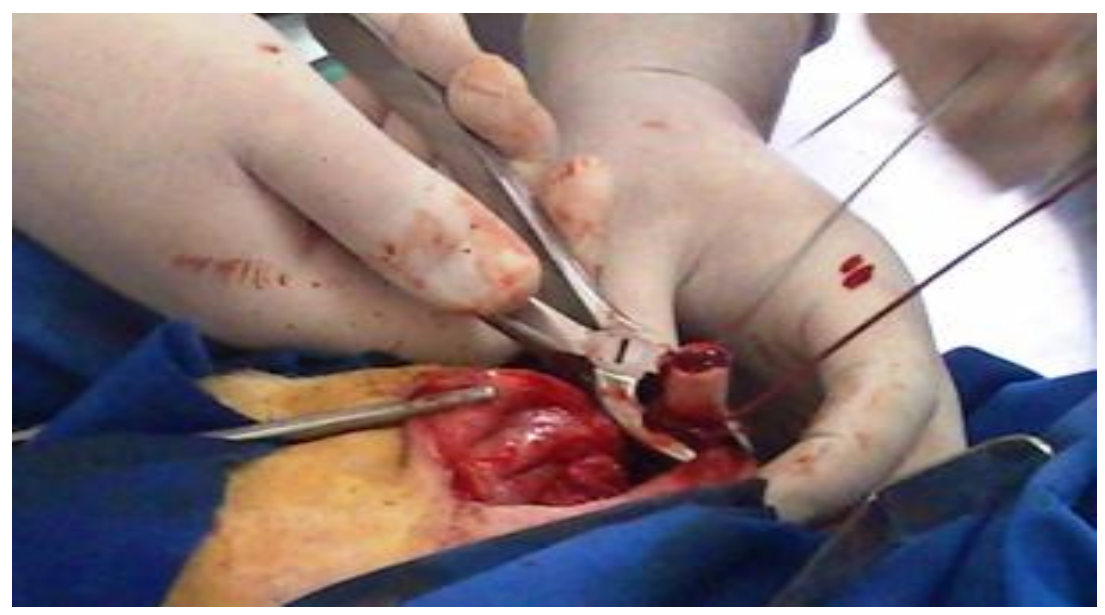

Figure-3.intraoperative photograph showing the introduction of the pin with a mandrel into the proximal femoral diaphysis, until its outlet at the trochanteric fossa.

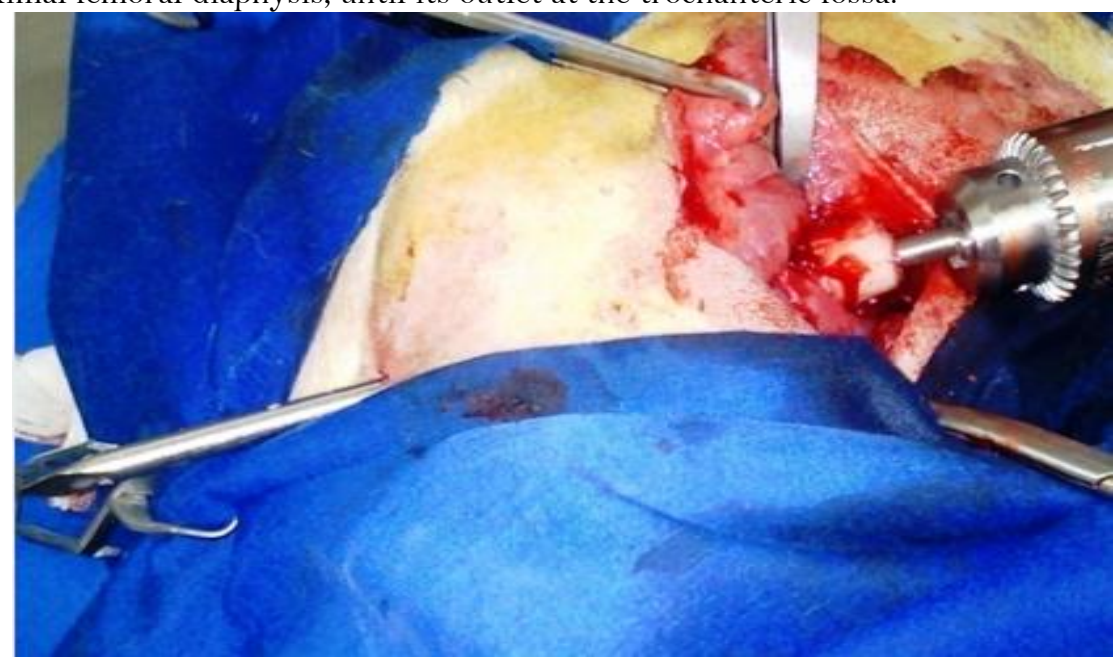

The complete insertion of the pin is estimated by a spindle of the same length in parallel with the pin lodged down, thereafter, the remainder thereof is cut with a cutting spindle.

The next step comprises applying a powder of antibiotic at both wound and then the fascia suture overlock a synthetic absorbable suture with polyglactin $0 / 2$. The closure of the skin is ensured by simple points separated polyamide $0 / 2$ and the wound is cleaned with betadine.

After injection of an analgesic, the animal is monitored until awakened, then placed in an individual cage in order to limit the movements.

\subsection{Radiological Monitoring}

Digital radiography (Camera Digital Radiography RAD-12 X-RAY Tube made for General Electric Company, Model 226680 serial 50431HL6, USA) performed each fifteen (15) days will allow us to assess the quality the callus, and the fate of the graft until withdrawal of spindle. Radiographs are taken in side view, to properly highlight the femur. The animal is sedated lying on the operated side with the nose gear rotated $45^{\circ}$. The free member is held vertically. 
Table-1. Radiographic results of the graft-host interaction.

\begin{tabular}{|c|c|c|c|c|}
\hline \multirow{2}{*}{\multicolumn{2}{|c|}{ Animals and type of graft }} & \multicolumn{2}{|c|}{ Osteoinduction } & \multirow{2}{*}{$\begin{array}{c}\text { Osteoconductio } \\
\mathbf{n}\end{array}$} \\
\hline & & Periosteal & medullary & \\
\hline \multirow{4}{*}{$\begin{array}{c}\text { Graft without } \\
\text { propolis }\end{array}$} & $\mathrm{N}^{\circ} 1$ & + & - & - \\
\hline & $\mathrm{N}^{\circ} 2$ & + & - & - \\
\hline & $\mathrm{N}^{\circ} 3$ & ++ & - & + \\
\hline & $\mathrm{N}^{\circ} 4$ & ++ & - & ++ \\
\hline \multirow{4}{*}{$\begin{array}{l}\text { Graft with } \\
\text { propolis }\end{array}$} & $\mathrm{N}^{\circ} 1$ & ++++ & ++++ & ++++ \\
\hline & $\mathrm{N}^{\circ} 2$ & ++++ & ++++ & ++++ \\
\hline & $\mathrm{N}^{\circ} 3$ & ++ & ++ & +++ \\
\hline & $\mathrm{N}^{\circ} 4$ & ++++ & ++++ & ++++ \\
\hline
\end{tabular}

Figure-5. The radiography shows development of the callus host always far from the graft without propolis

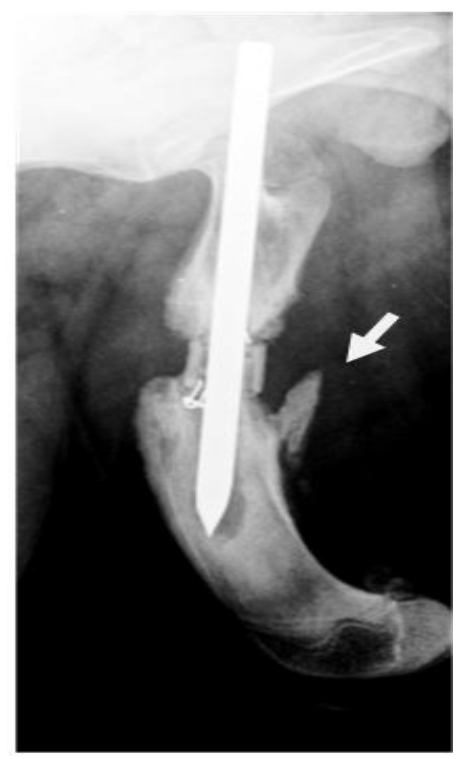

Figure-6. The radiography shows the development of the callus far from the graft without propolis
Figure-4. The radiographyshows apostoperativegraftimplemented the samediameter asthe recipient boneimmobilizedbysimple intramedullary nailingreinforced by astainlesswire.

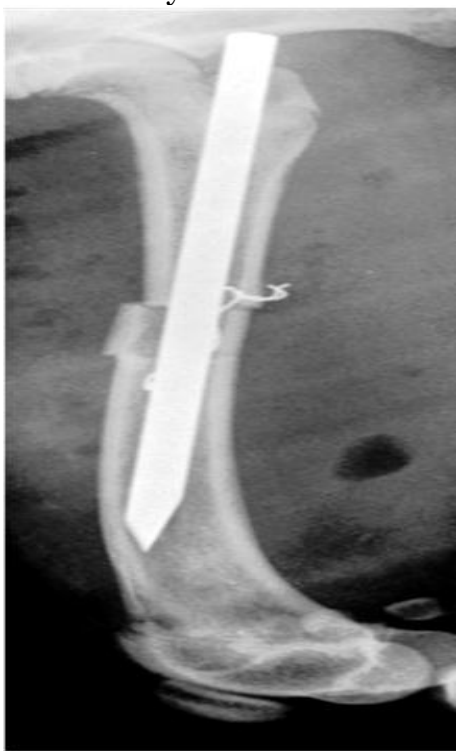

Figure-7. The radiography shows the earlier infiltration of the host bone directly on the graft covered by propolis. 

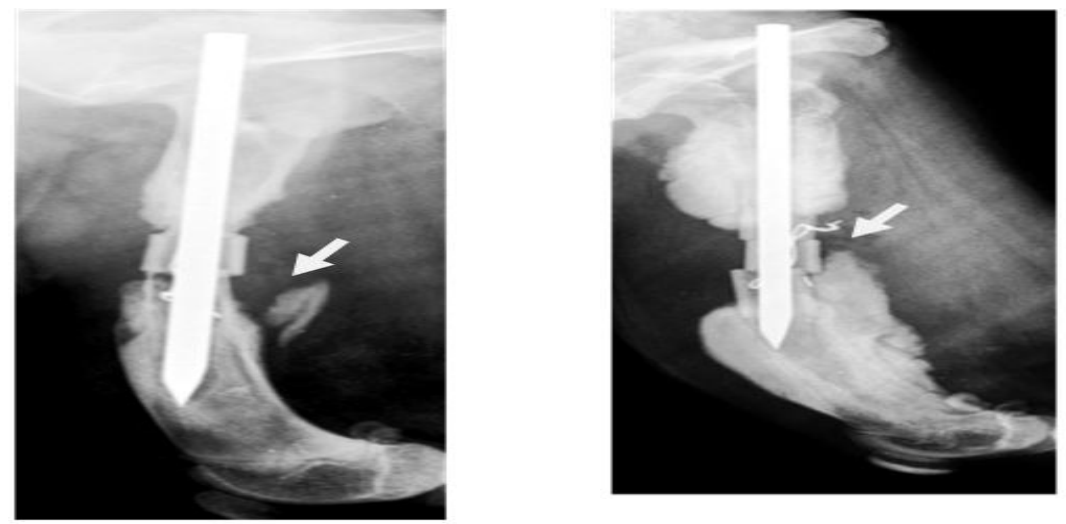

The propolis extract showed a regenerative power with regard to bone and cartilage, this is also

Health industry has always used the natural product as an alternative [5].Propolis extract has already demonstrated its efficiency, especially with the non-existence of side effects and adverse drug reaction following its use. $0.5-1 \%$ of the solutes was administered as an aerosol for the treatment of acute and chronic respiratory diseases and even as eye drops. 10\% alcoholic solutions have been used in disinfecting hands in the practice of dentistry. The beneficial effects of propolis appear to be worthy of their therapeutic efficiency [6]. The introduction of propolis in our study has opened new perspectives for the use of this substance in orthopedic surgery. The results of the clinical follow-up showed a recovery of all dogs treated with propolis graft covered with a minimum of post-operative complications. Currently, the propolis is studied due to its ability to improve the regeneration of bone loss [7]. This stimulatory effect was also obtained when using a graft covered with a thin layer of propolis. The intensity of osteoinduction observed in our study was proportionate to the amount of the graft covering with propolis. Propolis excess often caused excessive swelling at the operated region. A property of flavonoids which have antiinflammatory action and have the potential to stimulate the development of collagen. Propolis also helps in the development of bone bridge, it proved stimulating various enzyme systems, cell metabolism,circulation and collagen development [5].

Radiological results obtained show that the device in cases where callus autoclaved allogeneic grafts are covered with propolis was formed directly on the graftFigure $\mathrm{N}^{\circ} 7$,

while the callus where the grafts are uncovered formed remote from the graft. This explains the power of osteoconductive grafts covered with propolis which allows its matrix adhesion, cell proliferation and differentiation on which bone synthesis will be done Table $\mathrm{N}^{\circ} 1$.

The same results have shown that the stimulation of periosteal and medullary osteoinduction by propolis is causing the complete transition callus through both interfaces, unlike the control group where the callus moved to a limit not exceeding the limit of the graft Figure $\mathrm{N}^{\circ} 5$,6. At this time, a light ray "radio-transparent area" defines two interfaces of the graft bone. The periosteum role is to immobilize the fracture; which is essential situation for mineralization. Following the 
latter cortical do not participate in the development of callus. However, the bone marrow is the site of osteogenes in a strip located inside the cortical described by Mace [8].

\section{CONCLUSION}

The use of a thin layer of propolis on a autoclaved allograft, stimulated peripheral and spinal osteoinduction, and accelerated osseointegration at both proximal and distal interfaces, this phenomenon can be controlled depending on the amount used of propolis on the graft.

Osteoinduction cannot be achieved in a perfect way without osteoconductive power in our experiment; this has been accomplished by the graft covered with propolis which served as the foundation, capable of inducing bone development from bone recipient.

\section{REFERENCES}

[1] L. Miller and J. E. Block, "Prospective on the clinical utility of allograft for bone regeneration with osseous defects," Orthopedic Research and Reviews, vol. 3, pp. 31-37, 2011.

[2] D. Markel, S. Guthrie, B. Wu, Z. Song, and P. Wooley, "Characterization of the inflammatory response to four commercial bone graft substitutes using a murine biocompatibility model," $J$. Inflamm. Research, vol. 5, pp. 13-18, 2012.

[3] H. Razafimhandry, D. Randrianasolo, N. Andriamanana, and R. Randriarimangan, "Both use natural coral as a bone substitute," Medicine Africa Black, vol. 48, p. 114, 2001.

[4] L. Amorosa, C. Lee, A. Aydemir, S. Nizami, A. Hsu, N. Patel, T. Gardner, A. Navalgund, D. Kim, S. Park, J. Mao, and F. Lee, "Physiologic load-bearing charcacteristics of autogafts, allografts, and polymer-based scaffolds in a critical sized segmental defect of long bone an experimental study," $I$. J. Nanomedicine, vol. 8, pp. 1637-1643, 2013.

[5] A. Parolia, S. Thomas, M. Kundabala, and M. Mohan, "Propolis and its potential uses in oral health," I. J. Med. Medical. Sciences, vol. 2, pp. 210-215, 2010.

[6] J. Grange and R. Davey, "Antibacterial properties of the propolis (Bee Glue)," J Royal. Society. Med., vol. 83, p. 159, 1990 .

[7] A. Andrade, D. Manzi, and R. Zdomingues, "Tetracycline and propolis incorporation and release by bioactive glassy compounds, science directe," J Non-Crystalline Solids, vol. 352, pp. 3502-3057, 2006.

[8] Y. Mace, "Process of bone repair, service reform and rehabilitation of musculoskeletal and spinal pathologies," Cochin Hospital, Assistance Public Hospitals of Paris, pp. 2-5, 2007. 